\title{
ANÁLISE DA RESILIÊNCIA AOS EXTREMOS CLIMÁTICOS DE CHUVA: ESTUDO PRELIMINAR NA REGIÃO DE MAUÁ NO ABC PAULISTA - SÃO PAULO
}

ANALYSIS OF THE RESILIENCE TO EXTREME WEATHER OF RAINFALL:

A PRELIMINARY STUDY IN MAUÁ REGION IN ABC PAULISTA - SÃO PAULO

\section{Rafael Amorim Fernandes}

Engenheiro ambiental e urbano pela Universidade Federal do $A B C$ (UFABC) - Santo André (SP), Brasil.

\section{María Cleofé Valverde}

Professora Doutora do Curso de Engenharia Ambiental e Urbana da UFABC - Santo André (SP), Brasil.

\section{Endereço para correspondência:}

Rafael Amorim Fernandes -

Rua Francisco Luiz de Souza Junior, 350 - Água Branca - 05037-001 São Paulo (SP), Brasil - E-mail: rafael.afernandes@hotmail.com

Recebido: 01/09/2016

Aceito: $12 / 03 / 2017$

\section{RESUMO}

Eventos climáticos extremos e localizados impactam, principalmente, populações mais suscetíveis socioeconomicamente, com maior grau de exposição e menor resiliência. A fim de avaliar a resiliência de moradores das ruas mais afetadas por eventos extremos de chuva, no bairro Jardim Zaíra, ABC Paulista, um questionário foi elaborado com base em padrões comportamentais e aplicado em uma amostra da população. Os resultados mostram o grau de fragilidade socioeconômica e demográfica dos moradores, devido ao grande adensamento populacional, à baixa renda familiar, às deficiências no saneamento básico, à baixa expectativa de vida e à carência em estudos. Os padrões e extremos de chuva na região apontam a diminuição no acumulado mensal de chuva e o aumento na concentração diária, favorecendo eventos extremos. A análise das entrevistas indica resiliência média na amostra, ou seja, capacidade razoável para enfrentar crises e adversidades, com algum distresse e moderado sucesso, tendo forte contribuição do padrão religioso para um maior grau de resiliência.

Palavras-chave: resiliência; eventos extremos de chuva; mudanças climáticas; vulnerabilidade; Mauá.

\section{ABSTRACT}

Located and extreme climatic events impact, especially, the most socioeconomically susceptible populations, with higher levels of exposure and less resilience. In order to analyze the resilience of residents of the streets most affected by extreme rainfall events in Jardim Zaíra, ABC Paulista, a questionnaire was developed based on behavioral patterns and implemented in a sample of the population. The results show the degree of socioeconomic and demographic weakness of the neighborhood residents, due to the population density, low income, deficiencies in basic sanitation, low life expectancy and lack of studies. The patterns and extremes of rainfall point to a decrease in the annual accumulated rainfall and an increase in their daily concentration, favoring extreme events. The analysis of resilience indicates the sample has medium resilience, that is, reasonable ability to face crises and adversity, with some distress, and moderate success, with strong contribution of the religious standard to greater the resilience degree.

Keywords: resilience; extreme events of rainfall; climate change; vulnerability; Mauá. 


\section{INTRODUÇÃO}

Após a revolução industrial, as emissões de gases do efeito estufa (GEEs) têm aumentado, com destaque para a produção de dióxido de carbono $\left(\mathrm{CO}_{2}\right)$, que já ultrapassou o limite considerado seguro pela ciência, de 350 partículas por milhão (ppm), mantendo-se acima do nível de 400 ppm (NASA, 2015). O aumento nos GEEs está associado às mudanças climáticas, de modo que contribui para uma maior frequência e intensidade de eventos extremos localizados. Eventos extremos são caracterizados por aumento ou diminuição significativos de um determinado estado climático, de acordo com valores, frequência e associações temporais das observações, como chuvas, secas e ondas de calor intenso (MARENGO et al., 2010; UN-HABITAT, 2011).

Segundo o último relatório publicado pelo Painel Intergovernamental sobre Mudanças Climáticas (IPCC, sigla em inglês), a temperatura global deverá aumentar pelo menos $4^{\circ} \mathrm{C}$ até 2100 na comparação com o nível da era pré -industrial, intensificando os eventos extremos e gerando significativos impactos ambientais e sociais, como escassez de recursos naturais, desastres ambientais, fome e migrações das populações mais afetadas (IPCC, 2014).

Além de contribuírem significativamente para a intensificação das mudanças climáticas, as áreas urbanas sofrem grandes impactos devido aos efeitos da mudança no clima. As populações mais pobres e carentes de infraestrutura são as principais afetadas pelos eventos extremos, por estarem, geralmente, localizadas em áreas de risco, vulneráveis aos desastres naturais, além de possuírem menor capacidade de resposta aos seus impactos (MARTINS \& FERREIRA, 2011). Cardona (2004) identifica três componentes principais para a composição da vulnerabilidade: exposição; fragilidade social e econômica; e falta de resiliência.

Assim, pode-se considerar que a vulnerabilidade de um determinado sistema, grupo ou pessoa está relacionada, principalmente:

1. a uma componente física, que se refere ao grau de exposição em função da localização;

2. a uma componente socioeconômica e demográfica, que está relacionada à fragilidade social e econômica;

3. e a uma componente comportamental, comunitária e política, que está ligada à capacidade de resiliência, ou seja, à capacidade que um determinado sistema, grupo ou indivíduo tem de lidar com os impactos, respondendo e se reorganizando, de modo a manter sua estrutura, identidade e função (CARDONA, 2004).

Assim, este estudo aborda a resiliência como um aspecto importante a ser desenvolvido para a diminuição da vulnerabilidade.

Entender o quanto um sistema é suscetível ou incapaz de responder às mudanças climáticas permite a alteração de sua vulnerabilidade (IPCC, 2001). Ou seja, uma população que melhor responde a um estresse climático, como um evento de chuva extrema, será menos vulnerável aos seus impactos. Uma das formas de contribuir mais efetivamente para diminuir a vulnerabilidade de uma população é aumentar sua resiliência, entendendo quais fatores contribuem para sua alteração e buscando maneiras para aumentar sua resposta de adaptação.

A construção de formas de mensuração da resiliência envolve a complexidade da quantificação dos aspectos ligados aos fatores de risco e proteção assim como da avaliação das estratégias utilizadas por cada indivíduo na resolução dos problemas (ANGST, 2009). Ainda assim, na literatura bibliográfica (POLK, 1997; MARTINS; FERREIRA, 2010), é possível encontrar diversas metodologias que buscam capturar os principais aspectos do comportamento humano que ajudam a lidar com as adversidades.

Connor e Davidson (2003) construíram uma metodologia para medir a capacidade humana de prosperar frente à adversidade, o Connor-Davidson Resilience Scale (CD-RISC). Essa metodologia mede cinco fatores: competência pessoal, altos padrões e tenacidade; confiança nos próprios instintos, tolerância aos afetos negativos e fortalecimento pelos efeitos do stress; aceitação positiva de mudanças e relacionamentos seguros; controle e influências espirituais.

Reivich e Shattè (2002 apud BELANCIERI et al., 2010) também construíram uma ferramenta para identificar características ligadas à resiliência, o "Questionário do Coeficiente de Resiliência-RQ-Test", que possui 56 quesitos, variando de 1 (nunca verdade) a 5 (sempre verdade), e organiza a resiliência em 7 fatores: regulação das emoções; controle de impulsos; otimismo; análise causal; empatia; autoeficácia; e exposição. 


\section{OBJETIVO}

Este trabalho teve como objetivo estudar a resiliência de uma amostra de uma população vulnerável aos impactos dos extremos de chuva (deslizamentos, alagamentos e inundações), de forma a mensu- rar como ela reage e se mostra capaz de lidar com esses impactos. Também foram identificados os fatores que contribuem para o aumento ou para a diminuição da resiliência.

\section{MATERIAIS E MÉTODOS}

O município de Mauá está localizado na Região Metropolitana de São Paulo e pertence à Região do $A B C$ Paulista. O município possui uma área de $61,866 \mathrm{~km}^{2}$, com 448.776 habitantes (IBGE, 2014), sendo que aproximadamente $21 \%\left(12,44 \mathrm{~km}^{2}\right)$ do território total do município está localizado em área de proteção e recuperação aos mananciais, correspondentes à sub-bacia do rio Guaió. A cidade possui um grau de urbanização de $100 \%$, ou seja, a população urbana é correspondente à população total do município.

\section{Identificações de áreas vulneráveis aos extremos climáticos no município de Mauá - ABC Paulista}

A identificação das áreas vulneráveis às chuvas extremas teve como base o estudo desenvolvido por Valverde (2017), no qual foram identificados os municípios mais vulneráveis às chuvas extremas na região do ABC Paulista, e foram mapeadas as ocorrências de deslizamentos, inundações e alagamentos devido às intensas chuvas. Os resultados identificaram o município de Mauá como um dos mais vul-

\section{Avaliação da resiliência}

A avaliação da resiliência buscou entender a resposta de uma amostra da população aos impactos das chuvas extremas (inundação, alagamentos e deslizamentos). Dentre os métodos de mensuração da resiliência, não foi encontrada nenhuma aplicação específica que avalie a resposta de uma população aos impactos de eventos extremos de chuva. A abordagem sobre o tema, na maioria das vezes, está relacionada com a área da psicologia. Por esse motivo, para este trabaIho foram utilizadas as metodologias de Job (2003) e Polk (1997), as quais foram adaptadas com o propósito de avaliar graus de resiliência. Os autores estabelecem quatro padrões para avaliar atitudes e comportamentos que se relacionam com a resiliência (POLK, 1997):

- Padrão disposicional: adaptabilidade, autoafirmação, autocontrole, autodisciplina, autoestima, autossuficiência, capacidade de aprendizagem, capacidade de expressar emoções e senso de humor.

- Padrão relacional: capacidade de ajuda mútua, capacidade de comunicação e de estabelecer vínculos emocionais, flexibilidade e capacidade de formar relações. neráveis aos impactos de chuvas intensas. Com base nessa informação, o presente estudo identificou os bairros e ruas que sofriam mais impactos das chuvas, devido, principalmente, à sua exposição e à sua carência econômica e social. A base de dados foi a mesma utilizada no estudo de Valverde (no prelo), a qual foi disponibilizada pela Defesa Civil de Mauá para o período 2012-2014.

- Padrão situacional: acreditar em sorte criando opções, usar o bom senso, capacidade de lidar com a imprevisão e de ter metas futuras, vida mental rica no sentido de multiplicidade de interesses e criatividade.

- Padrão filosófico ou religioso: crer em um sentido de vida, ter esperança, ter crenças.

Com base nesses padrões, são criados questionários (JOB, 2003) para aplicar em amostras da população e, por meio do tratamento dos dados obtidos, inferir sobre escalas de resiliência.

O questionário é um instrumento importante para o levantamento de dados por amostragem e possibilita coletar informação de pessoas acerca de suas ideias, sentimentos, planos, crenças, bem como origem social, educacional e financeira (FIN \& KOSECOFF, 1985; GÜNTHER, 1999).

No presente estudo, foi elaborado um questionário, constituído por 32 perguntas, que foram construídas seguindo os 4 padrões de resiliência sugeridos por Polk (1997), porém adaptados ao objetivo deste tra- 
balho. O questionário (Quadro 1 ) teve 8 perguntas para cada padrão e a pergunta base foi: “Como está sua capacidade de enfrentar os impactos de um evento extremo de chuva, seja um deslizamento de terra ou uma inundação?".

No questionário (Quadro 1), foram construídas oito perguntas relacionadas ao padrão disposicional, que avalia o autocontrole, a capacidade de aprendizagem e a adaptabilidade (POLK, 1997), características importantes, que farão a diferença para uma comunidade que enfrenta o perigo de um evento extremo de chuva. Nesse contexto, as duas primeiras questões estiveram relacionadas ao interesse de saber sobre assuntos relacionados com a ocorrência de desastres, uma vez que, os moradores vivenciam esse risco em épocas de chuva, as outras questões buscaram entender a capacidade do morador em se adaptar e seu autocontrole frente à ocorrência de um desastre.
Para o padrão relacional (Quadro 1), que avalia a capacidade de ajuda mútua e comunicação para minimizar impactos (POLK, 1997), a primeira questão construída buscou entender a capacidade do morador de interagir com as outras pessoas em caso de desastres. A partir dessa questão, as outras foram construídas visando aprofundar o grau de comunicação e a ajuda mútua das pessoas que vivem em comunidades de risco, quando expostas a situações de perigo.

O padrão situacional (Quadro 1) avalia a capacidade de lidar com a imprevisão, de estabelecer metas futuras e de cultivar uma multiplicidade de interesses (POLK, 1997). Nesse padrão, a primeira pergunta construída buscou entender a percepção do risco, especificamente do local onde as pessoas moram. A partir disso, as outras questões buscaram aprofundar o aspecto de planos futuros e o cuidado que se deve ter com o local onde se mora, além de enfatizar que a solução

Quadro 1 - Ficha de avaliação da resiliência.

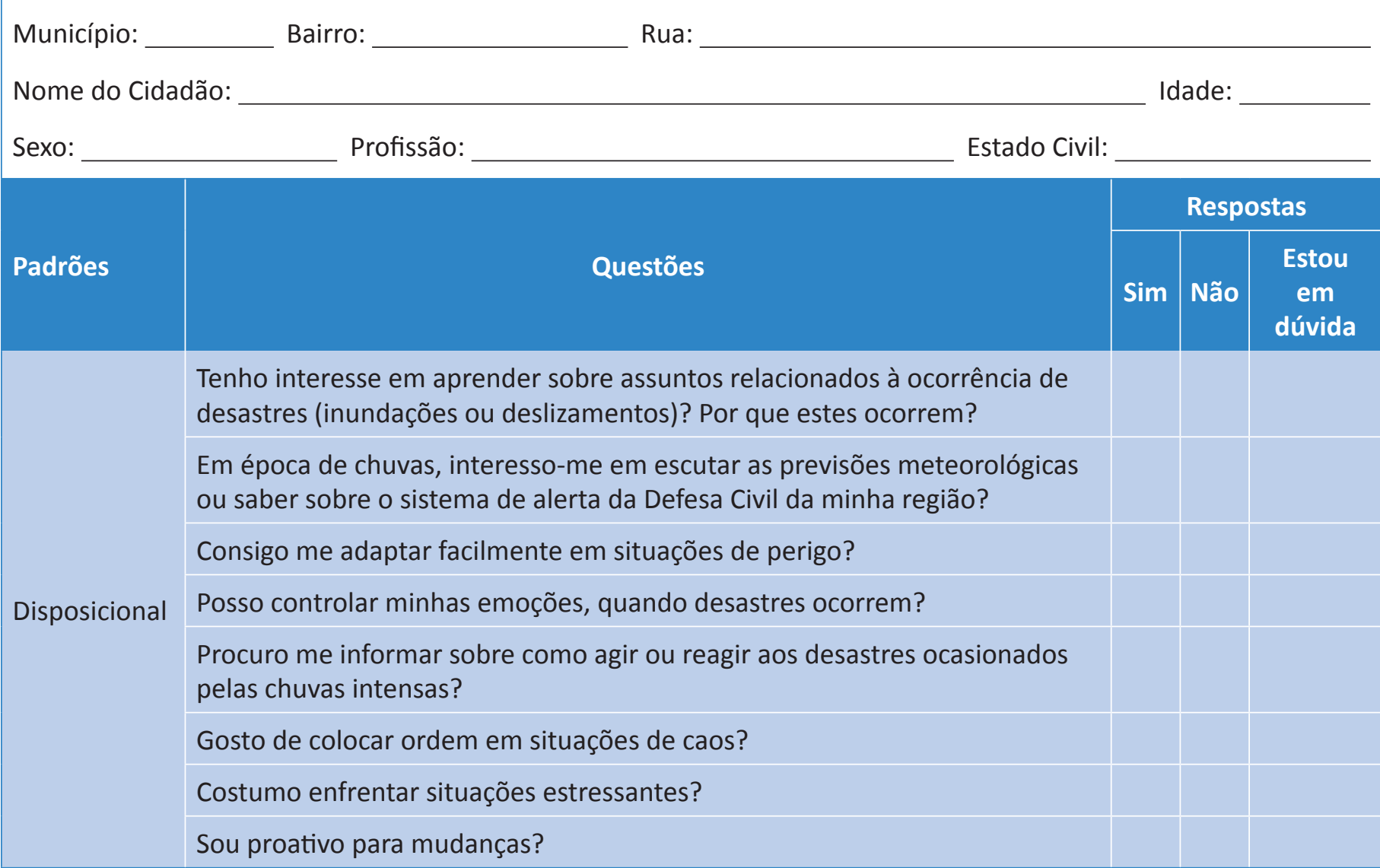




\section{Quadro 1 - Continuação.}

\begin{tabular}{|c|c|c|c|c|}
\hline \multirow[b]{2}{*}{ Padrões } & \multirow[b]{2}{*}{ Questões } & \multicolumn{3}{|c|}{ Respostas } \\
\hline & & Sim & Não & $\begin{array}{l}\text { Estou } \\
\text { em } \\
\text { dúvida }\end{array}$ \\
\hline \multirow{8}{*}{ Relacional } & $\begin{array}{l}\text { Faço parte de grupos que se organizam para melhor atuar em caso } \\
\text { de desastres? }\end{array}$ & & & \\
\hline & Confio nas pessoas ao meu redor quando preciso de ajuda? & & & \\
\hline & Sou tolerante? & & & \\
\hline & Sou predisposto em ajudar o próximo em situações não previstas? & & & \\
\hline & Emociono-me com a situação de outras pessoas? & & & \\
\hline & Sou uma pessoa de fácil convívio? & & & \\
\hline & Gosto de fazer amizades? & & & \\
\hline & Sou comunicativo? & & & \\
\hline \multirow{8}{*}{ Situacional } & $\begin{array}{l}\text { Considero morar em uma área de risco, onde as chuvas fortes podem } \\
\text { causar prejuízos? }\end{array}$ & & & \\
\hline & Tenho planos para o futuro? Por exemplo, mudar o local de moradia? & & & \\
\hline & Colaboro com a limpeza das áreas próximas? & & & \\
\hline & Gosto de me envolver e realizar novos projetos? & & & \\
\hline & Atuo diante de problemas mesmo sem saber a melhor alternativa? & & & \\
\hline & Já me recuperei de algum desastre ocasionado pelas fortes chuvas? & & & \\
\hline & Sou capaz de aprender com os desafios enfrentados? & & & \\
\hline & $\begin{array}{l}\text { Os problemas que atingem meu bairro podem ser solucionados por outras } \\
\text { pessoas além do prefeito? } \\
\text { Se não, acredito que o prefeito é o único responsável por solucionar os } \\
\text { problemas que atingem meu bairro. }\end{array}$ & & & \\
\hline \multirow{8}{*}{$\begin{array}{l}\text { Filosófico ou } \\
\text { Religioso }\end{array}$} & Tenho fé que algum dia as coisas vão melhorar? & & & \\
\hline & Preocupo-me com a avaliação negativa de meus atos? & & & \\
\hline & Tenho um objetivo de vida? & & & \\
\hline & Tenho fé que posso vencer qualquer situação adversa? & & & \\
\hline & Acredito receber forças divinas para enfrentar meus problemas? & & & \\
\hline & $\begin{array}{l}\text { Tento manter influência positiva sobre as mudanças que ocorrem à } \\
\text { minha volta? }\end{array}$ & & & \\
\hline & Minha fé me ajuda a atingir meus objetivos? & & & \\
\hline & $\begin{array}{l}\text { Acredito que os desastres acontecem por culpa do homem e não por um } \\
\text { castigo Divino? }\end{array}$ & & & \\
\hline Outras & \multicolumn{4}{|c|}{$\begin{array}{l}\text { Qual foi o episódio mais intenso de inundação ou deslizamento por chuva intensa que já vivenciei? } \\
\text { Especificar, ano, mês, dia e o impacto (perdas), se possível: }\end{array}$} \\
\hline
\end{tabular}

Fonte: Autoria própria com base nos modelos estudados. 
dos problemas também é de responsabilidade dos próprios moradores.

E para o último padrão filosófico ou religioso, que avalia a crença em um sentido para a vida, a esperança e as crenças religiosas (POLK, 1997), as questões construídas avaliaram de diferentes formas a fé e o pensamento positivo das pessoas perante exposição ao perigo. A fé pode direcionar e motivar uma ação positiva impulsionando a disposição, a comunicação, a proatividade e a ajuda mútua.

Embora o significado da palavra questionário possa ser definido como um conjunto de perguntas sobre um determinado tópico que não testa a habilidade do respondente, mas mede sua opinião e seus interesses principalmente (FIN \& KOSECOFF, 1985), o questionário criado neste estudo foi direcionado para um público alvo: pessoas que de alguma forma já foram impactadas por eventos de deslizamentos, alagamentos ou inundações, pertencentes a ruas identificadas como as mais vulneráveis aos eventos de chuva extrema. Tal questionário não foi aplicado de forma aleatória, evitando ser apenas uma pesquisa de opinião. Segundo Schuman e Kalton (1985), na elaboração de um questionário é importante ter muito claro o objetivo da pesquisa, em termos dos conceitos a serem pesquisados e a população alvo que se deseja atingir, podendo se obter dessa forma uma maior representatividade dos resultados.
Para o preenchimento do questionário, o entrevistado tinha opção de respostas divididas em "SIM", "NÃO" e "ESTOU EM DÚVIDA". A medida utilizada para a análise dos dados se deu por meio da soma dos pontos das questões avaliadas, tanto para o conjunto total quanto para cada padrão: padrão disposicional (PD), padrão relacional (PR), padrão situacional (PS) e padrão filosófico ou religioso (PF). Assim, o valor máximo que pode ser alcançado, por cada padrão, é 80 e o valor mínimo é 40 .

Para cada tipo de resposta (SIM, NÃO e ESTOU EM DÚVIDA), as informações obtidas foram tratadas estatisticamente e os resultados mostrados por meio de diagramas de Box-plot. Esse tipo de diagrama fornece características da medida da posição central dos dados (mediana), variabilidade ou dispersão dos dados (por meio dos quartis: 25, 50 e 75\%), valores máximos e mínimos, e os outliers (SEWARD \& DOANE, 2014).

Para a determinação das escalas de resiliência, utilizouse a classificação de Job (2003), com os tipos: resiliência alta, resiliência média alta, resiliência média e resiliência baixa. Para cada uma das escalas, foram atribuídos intervalos do Percentil 90 (Tabela 1), tendo como base os valores máximo e mínimo das pontuações obtidas nas respostas do questionário (Quadro 1). O Percentil é uma técnica que divide o conjunto de dados em cem partes iguais, onde, por exemplo, o $1^{\circ}$ percentil determina o valor em que $1 \%$ dos dados são menores que ele, e o $98^{\circ}$ percentil determina o valor em que $98 \%$ dos dados são menores que ele (SILVA, 2009).

\section{Análise de indicadores sociais, demográficos, sanitários e econômicos, nos bairros de Mauá}

Para a análise dos indicadores sociais, demográficos, sanitários e econômicos, foram utilizadas as informações da Prefeitura de Mauá que - por meio da Seção de Informações Socioeconômicas e da Coordenadoria de Planejamen- to Urbano - forneceu os dados de 2010, de acordo com a divisão oficial do município (21 Regiões de Planejamento ou Áreas de Ponderação). Das informações disponibilizadas, foram utilizados como indicadores:

Tabela 1 - Escala da Resiliência por meio do Percentil.

\begin{tabular}{cc} 
Classificação & $P(90$ th $)$ \\
\hline Resiliência alta & $P(90$ th $)=80$ \\
\hline Resiliência média alta & $80>P(90$ th $) \geq 76$ \\
\hline Resiliência média & $76>P(90$ th $) \geq 50$ \\
\hline Resiliência baixa & $50>P(90$ th $) \geq 40$
\end{tabular}


- demográfico-urbano (densidade demográfica);

- socioeconômico (taxa anual de crescimento do rendimento domiciliar médio, riqueza, pobreza, escolaridade e longevidade); e

- saneamento (serviço sanitário e abastecimento de água).

\section{Análises das chuvas e dos eventos extremos}

Para a análise, foram utilizados históricos de dados de chuvas diárias de três pluviômetros localizados no município de Mauá, obtidos do Departamento de Águas e Energia Elétrica (DAEE): Mauá (E3-148), Noêmia (E3-156) e Zaíra (E3-157). A estação pluviométrica E3-148 possuía dados de 1953 até 2003 (51 anos), motivo pelo qual ela foi considerada para representar a climatologia da área de estudo. As estações E3-156 e E3-157 possuem dados de um período mais curto, porém, mais recente, de 1999 até 2015 (16 anos), sendo também utilizadas na análise devido à atualidade dos dados.

As informações de chuvas foram processadas em planilhas, para análise do padrão mensal climatológico,
A análise dos indicadores auxiliou na identificação da fragilidade social e econômica da região de estudo, componente da vulnerabilidade que analisa os fatores socioeconômicos e demográficos e captura a predisposição de um grupo populacional de sofrer diante de um fenômeno perigoso. Segundo Cardona (2004), tal predisposição é decorrente do grau de marginalidade, da segregação social e da fragilidade econômica às quais um determinado grupo populacional se encontra submetido.

das tendências dos acumulados anuais, da variabilidade diária e dos eventos diários máximos de chuva na época de verão. A análise de tendências indica movimentos graduais e sistemáticos ao longo do intervalo de dados, em que há elevação ou diminuição dos valores médios da série. A tendência pode ser obtida por meio da equação linear: $Y=a+b X$. Onde $Y$ refere-se à variável dependente e $X$ corresponde ao período. $O$ termo "a" é a intersecção no eixo $Y$ e " $b$ " é o coeficiente angular da reta, o qual pode ser obtido por meio da série de $n$ dados (PETERNELLI, 2014). Para evidenciar casos extremos de mínima e/ou máxima precipitação, os percentis 15 e $95 \%$ foram calculados, respectivamente.

\section{RESULTADOS}

\section{Análise das áreas vulneráveis aos extremos de chuva, no município de Mauá}

A análise dos 28 bairros que constituem o município de Mauá mostrou que o bairro Jardim Zaíra é o mais vulnerável às chuvas intensas, devido ao maior número de eventos (41), quando comparado com outros bairros. Dessas 41 ocorrências, 2 foram inundações, 6 alagamentos e 33 de deslizamentos, para o período de 2010 a 2014 (Figura 1).

Em segundo lugar, o Jardim Oratório apresentou a maior frequência de ocorrências, 29 no total, sendo 1 inundação, 8 alagamentos e 20 deslizamentos (Figura 1). Tanto para o Jardim Zaíra quanto para o Jardim Oratório, a maioria das ocorrências esteve relacionada com eventos de deslizamentos. Essas estatísticas foram realizadas tendo como base os registros históricos de ocorrências da Defesa Civil de Mauá.

O Jardim Zaíra é o bairro mais populoso de Mauá, com cerca de 110 mil habitantes, quase $1 / 4$ (um quarto) da população do município. O bairro teve crescimento considerável ao longo dos anos e é dividido em microrregiões, conhecidas como Jardim Zaíra de I a VII e Macuco.

A partir da identificação do Jardim Zaíra como o bairro mais representativo para o impacto dos eventos extremos de chuva, foram mapeadas as ruas do bairro com o maior número de ocorrências: as 41 registradas ocorreram em 32 ruas do bairro, em sua maioria ligadas a deslizamento; a minoria das ocorrências estavam relacionadas a inundações. Dentre as ruas com maior ocorrência de deslizamentos, inundações e alagamentos, algumas foram selecionadas para a aplicação do questionário para avaliar a resiliência de seus moradores. Assim, levando em conta áreas com maior potencial para ocorrência desses eventos, junto com a Defesa Civil de Mauá, foram escolhidas as seguintes ruas para visita: Rua Lourival Portal da Silva, Rua Eugênio Negri, Rua Rosa Gabioneta, Rua Manoel Nascimen- 
to, Rua Maria Dominiquini e Rua Moacir Campos do Nascimento. Além dessas, as Ruas Júlio Antônio Conde e Manoel Nascimento também foram visitadas, por indicação da Defesa Civil de Mauá.

Com a visita aos locais, sempre na companhia de um agente da defesa civil, foi possível perceber que as re- giões com o maior número de ocorrência de eventos ligados à chuva intensa possuem grande adensamento populacional, e, muitas vezes, estão próximas a áreas suscetíveis a deslizamento, ou seja, áreas de risco geológico-geotécnico, devido a construções próximas a encostas e ao despejo irregular de efluentes e lixo.

\section{Análise de indicadores sociais, demográficos, sanitários e econômicos no Jardim Zaíra}

A análise dos indicadores fornecidos pela Prefeitura de Mauá mostrou que o bairro do Jardim Zaíra, quando comparado com os outros bairros, apresenta alta concentração populacional, com mais de 16 mil pessoas por km² em três regiões do Zaíra (Zaíra II; Zaíra III e IV; e Macuco) e uma baixa taxa de crescimento do rendimento domiciliar médio ${ }^{1}$, apresentando taxa negativa para o Jardim Zaíra II.

${ }^{1}$ Calculada por setores censitários, por meio da equivalência dos setores de 2000 e 2010, e atualizada pelo IPCA (IBGE), para o cálculo da taxa de geométrica crescimento.
A porcentagem dos moradores com renda familiar per capita maior a dois salários mínimos se mostrou baixa para a região do Zaíra. O Macuco, área do Jardim Zaíra em que foi realizada a maior parte das entrevistas, apresentou a menor porcentagem (Figura 2). 0 índice da população com renda familiar per capita menor que $1 / 2$ (meio) salário mínimo mostrou o Jardim Zaira III e IV e o Macuco com uma das mais altas porcentagens (Figura 2), caracterizando a baixa remuneração dos moradores dessa região. Maior vulnerabilidade econômica, muitas vezes, implica, também, em um fator de risco que ameaça o bem-estar das pessoas, limitando suas oportunidades de desenvolvimento (CECCONELLO, 2003).

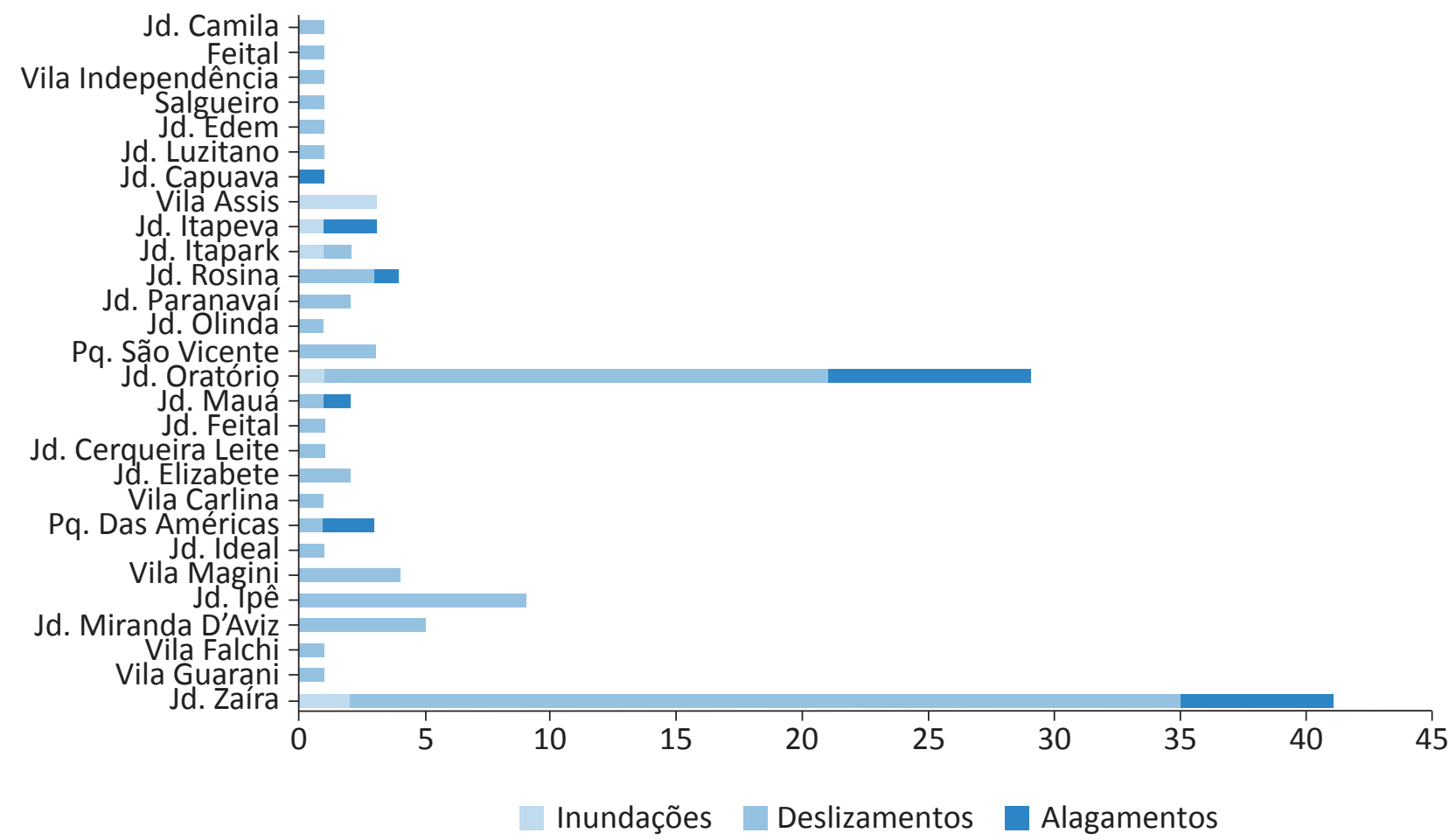

Figura 1 - Frequência de eventos de deslizamentos, alagamentos e inundações, relacionados à chuva intensa, em bairros de Mauá, para o período de 2010 a 2014. 
A região do Macuco também se destaca pelo alto índice de pessoas com 15 anos de idade ou mais com menos de 4 anos de estudo, assim como pela baixa expectativa de vida. Além disso, uma grande parcela dos domicílios, principalmente na região do Macuco, não tem serviço sanitário (rede pública ou fossa) e apresenta deficiência no abastecimento de água.

Com os resultados descritos acima, nota-se que a região do Jardim Zaíra, principalmente o Macuco, área onde foi realizada a maior parte das entrevistas, possui um grande adensamento populacional, baixa renda familiar, deficiência de serviços de saneamento básico, baixa expectativa de vida e um número alto de pessoas sem muitos anos de estudo. Sendo assim, esse bairro e sua população se diferenciam, de uma forma geral, dos outros bairros no município de Mauá, pela sua fragilidade social e econômica, caracterizando-se como um dos mais vulneráveis social e economicamente, o que contribui também para deixá-lo mais exposto ao impacto de chuvas extremas e outros extremos climáticos.

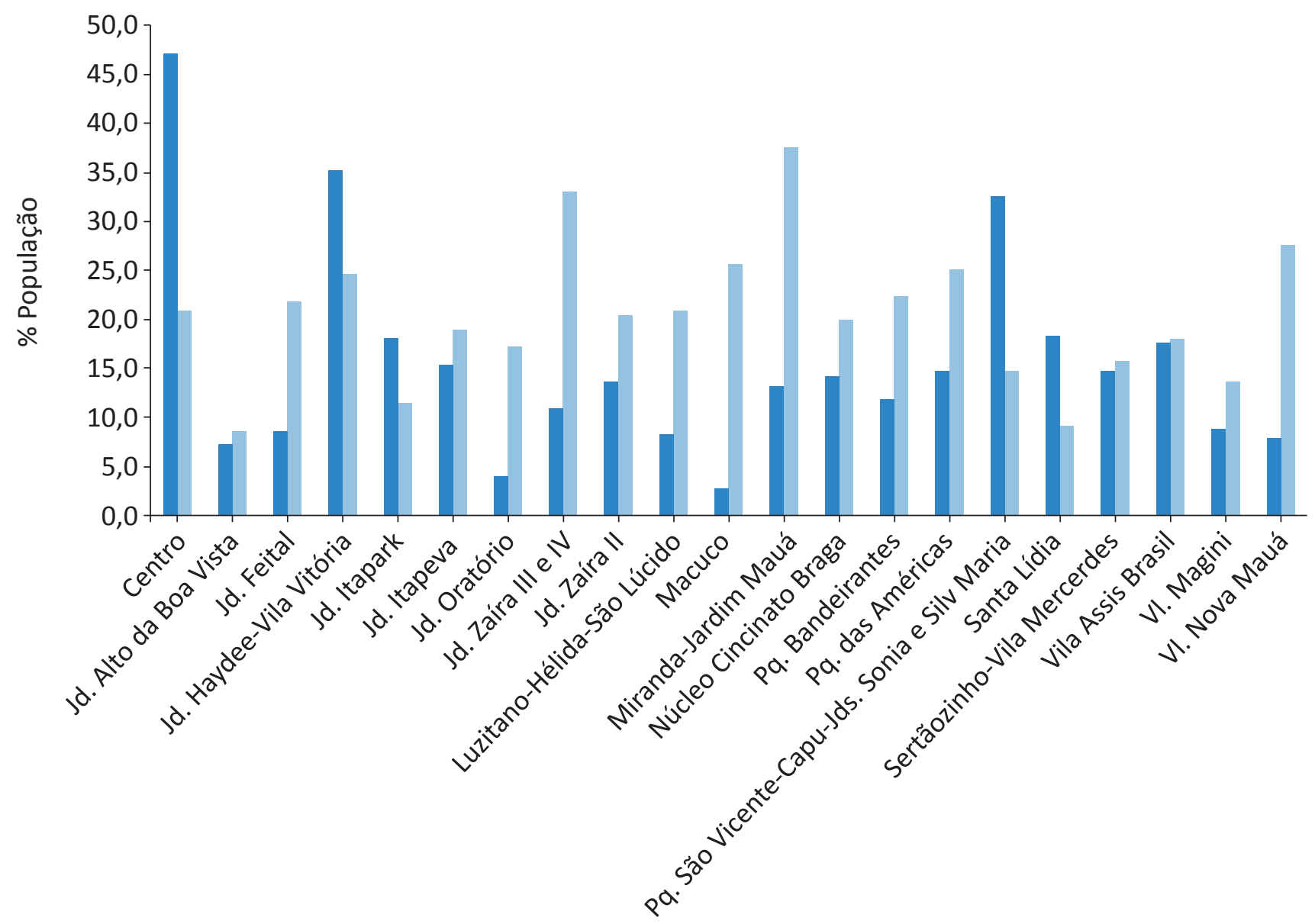

Renda familiar per capita maior a 2 salários mínimos.

Renda familiar per capita menor a $1 \frac{1}{2}$ salário mínimo.

Figura 2 - Porcentagem da população com renda familiar, per capita, maior a dois salários mínimos e menor a $1 / 2$ salário mínimo nos bairros de Mauá. 


\section{ANÁLISE DE DADOS DE CHUVA NO MUNICÍPIO DE MAUÁ}

Utilizando os dados de precipitação dos três pluviômetros, foi possível identificar o padrão sazonal da chuva: a maior intensidade de chuvas ocorre no período de verão - dezembro, janeiro e fevereiro; e a menor intensidade no inverno - junho, julho e agosto (Figura 3A). Em todas as estações pluviométricas, o mês que apre- sentou maior precipitação foi o de janeiro $(242,93 \mathrm{~mm}$ em Mauá, 227,65 mm em Noemia e 235,76 em Zaíra), seguido pelo mês de fevereiro (225,46 mm em Mauá, 186,65 mm em Noemia e 156,55 mm em Zaíra).

As médias mensais na Figura $3 \mathrm{~A}$ representam períodos diferentes, sendo que a estação pluviomé-

Precipitação média mensal

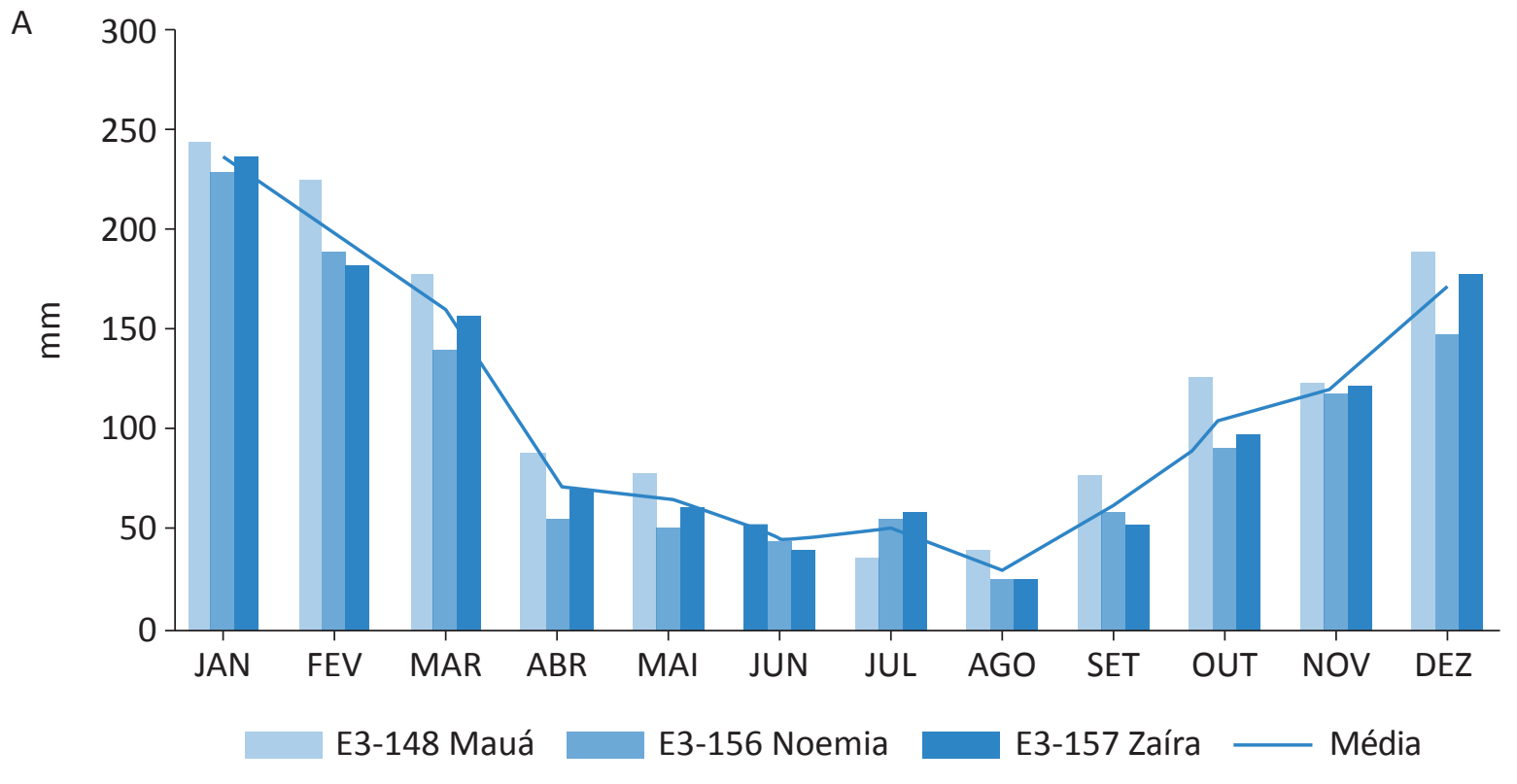

B

Precipitação diária máxima no verão

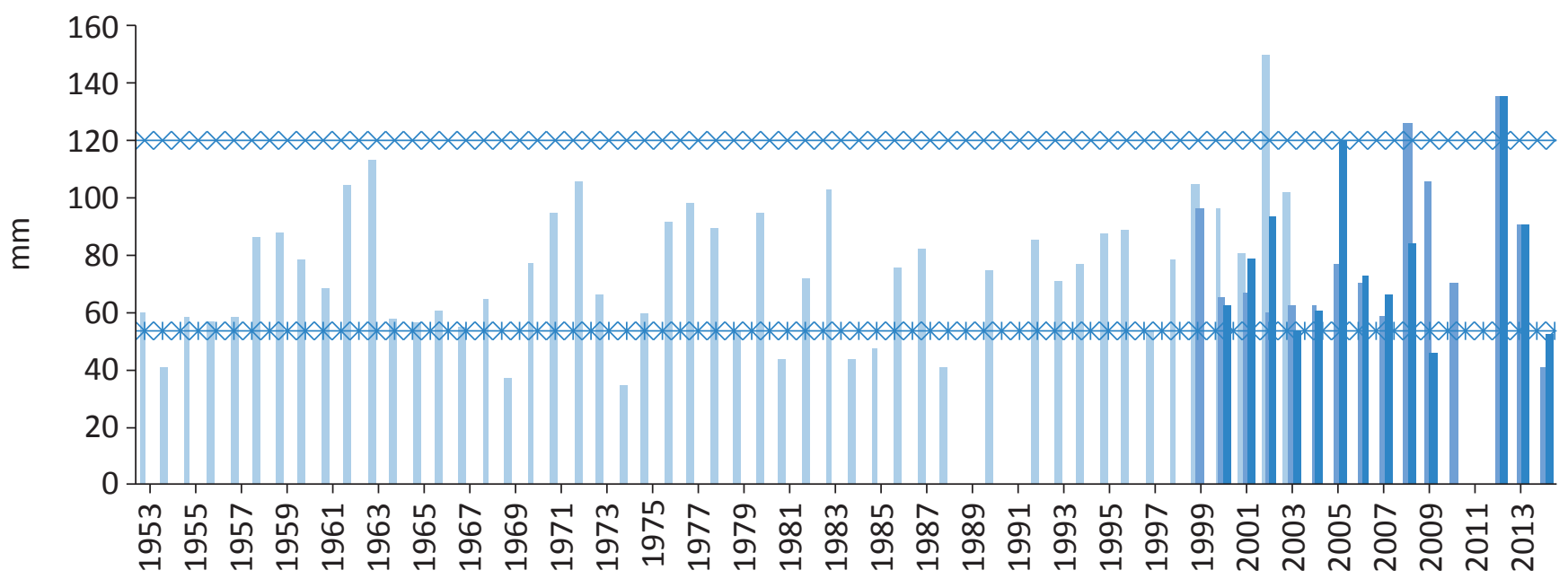

E3-148 Mauá

E3-156 Noemia

E3-157 Zaíra $\leftarrow$ Per 95\% $\rightarrow$ Per 15\%

Figura 3 - Média mensal das estações pluviométricas $(A)$ e variabilidade interanual da precipitação máxima diária no período de verão com os percentils 95\% (Per 95\%) e 15\% (Per 15\%) (B). 
trica de Mauá tem uma série histórica de 1953 até 2003 (51 anos), e a de Noemia e Zaíra apresentam dados de 1999 até 2014 (16 anos). A estação de Mauá apresenta maiores valores de precipitação média mensal, em comparação com as estações de dados mais recentes (Noemia e Zaíra); a diferença de precipitação entre elas é em média $14,95 \mathrm{~mm}$, no período de verão. A estação Zaíra, localizada na área de estudo, apresenta maior precipitação mensal do que a de Noemia, nos meses de dezembro e janeiro. Em média, no verão (dezembro, janeiro e fevereiro), a precipitação diminuiu $32,24 \mathrm{~mm}$, quando se compara a estação Mauá com Noemia, e 20,99 mm, quando se compara a estação Mauá com a Zaíra. Com isso, os resultados sugerem uma diminuição na precipitação média mensal, nos últimos 16 anos.

Ao considerar a precipitação diária máxima, apenas no período de verão (Figura 3B), época de maior intensidade das chuvas, observa-se que a estação Mauá (que possui o registro mais longo) apresenta uma tendência linear de aumento (em média $25 \mathrm{~mm}$ por dia). No entanto, essa série vai somente até o ano 2003. Por outro lado, as estações de Noêmia e Zaíra, de períodos mais recentes, retratam um comportamento mais atual dos máximos diários de verão. Para estabelecer os limiares de eventos extremos diários, o mínimo do máximo diário e o máximo do máximo diário de chuva, calcularam-se, respectivamente, os percentis 15 (\%), com o valor de $53,32 \mathrm{~mm}$, e $95(\%)$, com o valor de $120,16 \mathrm{~mm}$.

Observa-se na Figura 3B que, na estação de Mauá, em 51 anos, foi registrado apenas 1 evento extremo (acima do percentil 95\%), com um valor máximo diário de $150 \mathrm{~mm}$ em 2002. Já, para os dados mais recentes, em apenas 16 anos de observação, é possível verificar 2 anos com extremos máximos de chuva, 2008 (125,6 mm) em Noemia, e 2012 (135, 2 mm) em Zaíra e Noemia. O ano de 2005 (118,8 mm), em Zaíra, também se aproximou do percentil 95\%. Com isso, é possível notar uma maior frequência de eventos extremos de máximo de chuva na região de estudo, em um período menor de tempo. A Figura 3B também evidencia a maior frequência de picos extremos, tanto de mínimo quanto de máximo de chuva, com destaque, novamente, para uma tendência à diminuição de precipitação no período mais recente. Importante ressaltar que os mínimos da máxima chuva diária no verão de 2014 estão associados com a seca intensa que ocorreu em todo o estado de São Paulo e que foi um dos fatores que originou a crise nos reservatórios do Sistema Cantareira (VIANA, 2015).

As chuvas de verão no estado de São Paulo têm como causa principal a ocorrência do sistema atmosférico conhecido como a Zona de Convergência do Atlântico Sul (CARVALHO E JONES, 2009) e das Frentes Frias (CAVALCANTI \& KOUSKY, 2009), sendo esses mesmos sistemas responsáveis pelas chuvas na região do $A B C$ Paulista. Porém, a variabilidade espacial da chuva faz com que cada região específica se caracterize por uma intensidade, dependendo de fatores locais, como o tipo de ocupação de solo, orografia, vegetação, urbanização, entre outros.

$\mathrm{Na}$ análise das séries mais atuais de chuva (19992014), encontrou-se que, no Zaíra, a média mensal no verão é mais intensa que em Noêmia, e que houve um maior número de ocorrência de extremos. Isso pode estar associado com fatores locais, especificamente as características topográficas da região e a ocupação do solo. Segundo Conceição (2013), o município de Mauá apresenta topografia constituída por dois tipos de relevo - Morros com Serras Restritas e Colinas Pequenas com Espigões Locais. A estação de Noemia localiza-se em uma região com declividades que oscilam entre 3 e $20 \%$, já Zaíra se localiza em áreas com declividades maiores que $45 \%$, evidenciando que essa última região de estudo é essencialmente composta de morros e, por esse motivo, pode ser considerada área de risco geológico-geotécnico (CONCEIÇÃO, 2013).

A presença de morros para a geração de chuva se constitui como um fator importante para as chuvas orográficas. Por outro lado, o efeito do aquecimento intensificado pela ocupação e pela alteração do solo, que se somam a uma alta densidade da população, pode influenciar a convecção para a ocorrência de fortes chuvas. Esses fatores podem explicar, de uma forma geral, porque na região de estudo (Zaíra) a precipitação média mensal no verão é maior que em Noemia. 


\section{Avaliação da Resiliência nas áreas vulneráveis aos impactos das chuvas extremas, no Jardim Zaíra}

As entrevistas foram realizadas principalmente na região de Macuco, pertencente ao bairro Jardim Zaíra. Com o auxílio e a colaboração da Defesa Civil de Mauá, foram realizadas visitas e foram aplicados questionários aos moradores das ruas identificadas pela ocorrência de eventos de deslizamento, inundação e alagamento: Rua Lourival Portal da Silva, Rua Eugênio Negri, Rua Rosa Gabioneta, Rua Manoel Nascimento, Rua Maria Dominiquini, Rua Moacir Campos do Nascimento, Rua Júlio Antônio Conde e Rua Manoel Nascimento, a fim de mensurar e, posteriormente, avaliar a resiliência de uma amostra da população do bairro em estudo.

Foram entrevistadas 61 pessoas, no total, sendo 38 mulheres e 23 homens, 13 jovens ( 15 a 24 anos), 37 adultos ( 25 a 59 anos) e 11 idosos (com 60 ou mais), e 29 pessoas solteiras (incluindo viúvas e divorciadas, sem nova união) e 32 com parceiro fixo (união estável ou casados).

Os resultados das entrevistas, para a amostra da população, são mostrados no diagrama Box-plot (Figura 4), no qual observa-se a influência dos quatro padrões: PD
(Padrão disposicional), PR (Padrão relacional), PS (Padrão situacional) e PF (Padrão filosófico ou religioso) na resiliência das pessoas entrevistadas no Jardim Zaíra. Com a análise de todas as respostas, percebe-se que os padrões de comportamento PD e PR possuem variabilidade similar, com uma mediana de 70 , e com $75 \%$ das respostas entre 65 e 75 pontos. O padrão PD apresentou valores de 80 que indicam entrevistados com alta resiliência para esse padrão, e um outlier de 45 que também indica um entrevistado com baixa resiliência para esse padrão, como pode ser observado no limite do mínimo valor extremo.

O padrão PS também apresentou uma mediana de 70 pontos e uma maior variabilidade, com o primeiro quartil abaixo dos demais padrões, podendo influenciar para um menor valor de resiliência. Esse padrão avalia a criatividade e a capacidade de improvisar, no caso do presente estudo, diante da ocorrência de um deslizamento pelas fortes chuvas. De acordo com as respostas, o primeiro quartil do PS foi baixo devido ao fato de as pessoas entrevistadas responderem que não se envolvem em novos projetos relacionados com pre-

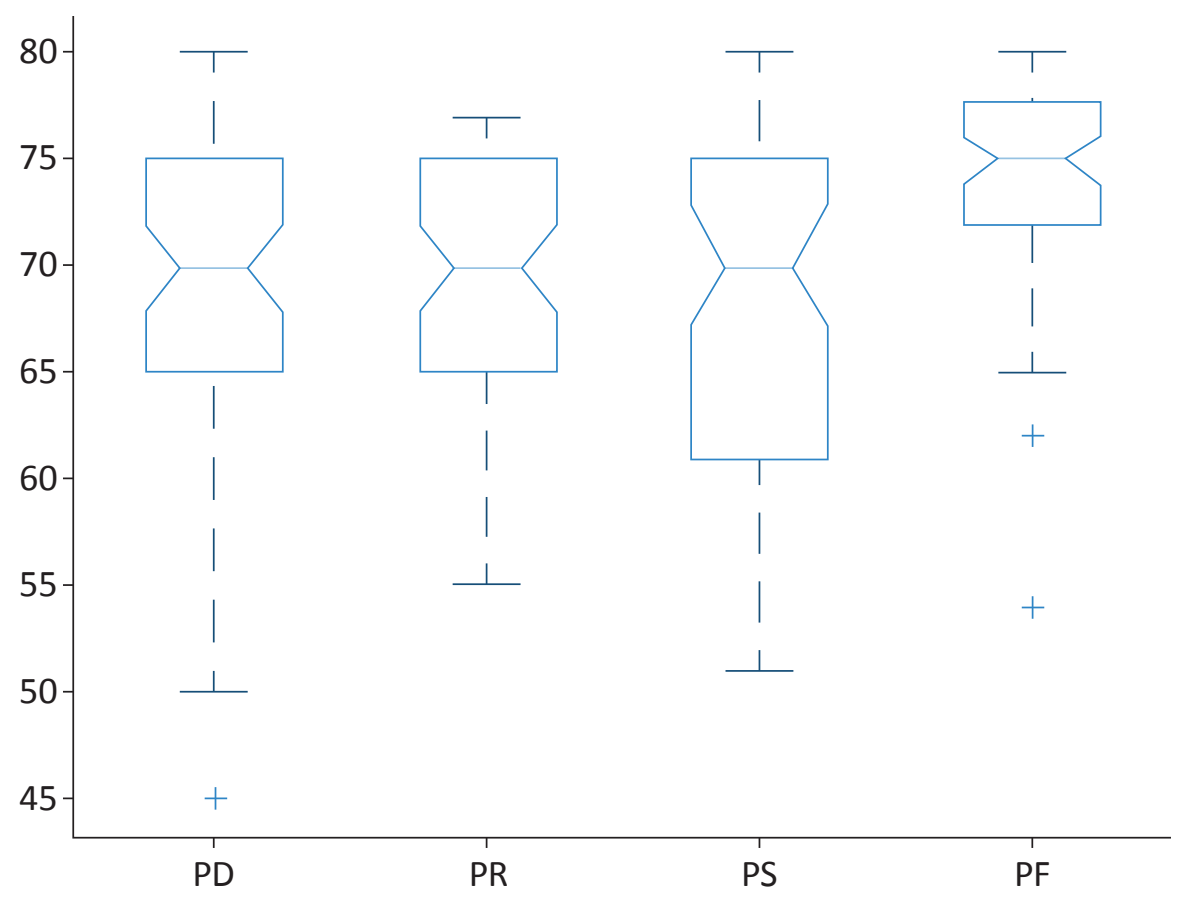

Figura 4 - Diagrama Box-plot para os padrões de comportamento que avaliam a resiliência na área de estudo. 
venção de desastres, nunca terem se recuperado de um desastre e não acharem que suas moradias estão localizadas em uma área de risco geológico-geotécnico.

O PF se destacou pela influência no aumento da resiliência dos entrevistados. Observa-se, na Figura 4, o PF com uma variabilidade menor, com mediana de 75 e com $75 \%$ dos valores entre 73 e 77 pontos. Esse padrão analisa a fé e a crença das pessoas, sendo assim, o resultado mostra que a maioria da população entrevistada tem uma crença muito forte em Deus, com exceção de duas das pessoas entrevistadas (os outliers, vistos na Figura 4). Os entrevistados mostraram ter uma confiança muito grande em relação à ajuda "Divina", mesmo frente às adversidades e perdas materiais ocasionados por um desastre. A fé e a participação em missas, como em outros grupos religiosos, podem contribuir para o bem-estar emocional, aliviando tensões e provendo energia para lidar com problemas (CECCONELLO, 2003). Além disso, a fé pode servir para suprir as necessidades de apoio instrumental e emocional para uma determinada pessoa (HOPE, 1998 apud CECCONELLO, 2003).

Nas áreas mais suscetíveis a eventos relacionados à chuva, onde a pobreza costuma ser frequente, a incidência de denominações evangélicas e do catolicismo praticante se faz importante, de modo que a religião age como agente mediador de carências familiares e coletivas, tanto materiais quanto espirituais, contribuindo para superação emocional e, ainda, podendo preencher as lacunas assistenciais não preenchidas pelo Estado (VALENCIO et al., 2009).

A Tabela 2 mostra a escala de resiliência, que teve como base o cálculo do percentil dos valores obtidos a partir de cada resposta. Dessa forma, os níveis de resiliência foram identificados para cada tipo de padrão e para o conjunto total. Os resultados apontam os padrões PF e PD como os mais influentes, sendo PF o único com resiliência alta e PD com resiliência média alta. Os padrões PR e PS apresentaram resiliência média. Como resultado dos quatro padrões, a resiliência total dessa amostra de população do Jardim Zaíra é uma resiliência média.

Segundo Sabbag (2012), resiliência média ou moderada significa razoável capacidade de enfrentamento de crises e adversidades, com algum distresse, e moderado sucesso.

$\mathrm{O} P \mathrm{P}$, que também contribuiu para um aumento na resiliência da amostra, analisa desde a adaptabilidade, autocontrole e autoestima até a capacidade de aprendizagem e de expressão de emoções. De acordo com as respostas dos questionários, esse padrão não foi mais alto, pois os moradores mostraram falta de interesse em aprender sobre assuntos relacionados à ocorrência de inundações e deslizamentos assim como não procuraram informações sobre como agir em caso de desastres relacionados à chuva.

O PR analisa a capacidade de comunicação e de formar relações. Nas entrevistas, as respostas que contribuíram para uma resiliência média, nesse padrão, estiveram associadas às pessoas que não participam de grupos que se organizavam para melhor atuar em caso de desastres, que se declararam pouco tolerantes e que não confiam nas pessoas ao redor, quando precisam de ajuda.

A interação e a relação entre as famílias podem atuar como um fator de proteção entre elas. Essa interação é importante para gerar um clima comunitário positivo, favorecendo um senso de identidade comunitária e compartilhando objetivos comuns (CECCONELLO, 2003). $O$ bom relacionamento com a vizinhança pode trazer redes de apoio social entre os moradores, tornando-se

Tabela 2 - Resultado do nível de resiliência para a amostra da população do Jardim Zaíra.

\begin{tabular}{|c|c|c|c|c|c|c|}
\hline Níveis & P(90th) & PD & PR & PS & PF & Total \\
\hline Resiliência alta & $P(90$ th $)=80$ & & & & $x$ & \\
\hline Resiliência média alta & $80>P(90$ th $) \geq 76$ & $\mathrm{x}$ & & & & \\
\hline Resiliência média & $76>P(90$ th $) \geq 50$ & & $x$ & $x$ & & $x$ \\
\hline Resiliência baixa & $50>P(90$ th $) \geq 40$ & & & & & \\
\hline
\end{tabular}


um importante recurso para lidar com os fatores de risco existentes na comunidade (CECCONELLO, 2003).

O PS - padrão relacionado com a criatividade, a criação de opções e a capacidade de lidar com a imprevisão e de cultivar uma multiplicidade de interesses - teve um baixo grau, pois, segundo as respostas, os moradores não se envolveram em novos projetos, não passaram pela recuperação de um desastre anterior e não consideraram estar em uma área de risco geológico-geotécnico. A multiplicidade de interesses pode contribuir para a presença de valores compartilhados, favorecendo o estabelecimento de redes de apoio social (MCMILLAN \& CHAVIS, 1986 apud CECCONELLO, 2003), contribuindo também para lidar com fatores externos. A criatividade está ligada com a geração de pensamentos alternativos e soluções criativas frente a uma situação de problema (GRECO et al., 2006 apud OLIVEIRA \& NAKANO, 2011), além de contribuir, de modo singular, para o enfrentamento de situações adversas (GONZÁLEZ, 2000 apud OLIVEIRA \& NAKANO, 2011).

Com os resultados obtidos por meio das entrevistas e tendo como base os padrões de Polk (1997), observou-se que a amostra da população do Jardim Zaíra tem uma resiliência média, em que o padrão filosófico ou religioso se mostrou alto e determinante, sendo um importante fator para uma maior resiliência na população.

Os padrões relacional e situacional contribuíram para a resiliência média dessa população. A maioria dos entrevistados não acredita morar em uma área exposta (vulnerável) aos impactos das chuvas intensas. A percepção da ameaça, nesse caso específico, as chuvas intensas, ainda não é clara para a maioria dos moradores, embora eles se lembrem de eventos com chuvas intensas, como é o caso específico de janeiro de 2011, quando quatro pessoas morreram na Rua Lourival Portal, devido aos deslizamentos e às inundações causadas pelas fortes chuvas, na região do Macuco, caso que também foi citado nos estudos de Conceição (2013).

O Jardim Zaíra apresenta diversas ocorrências de eventos relacionados à chuva, com impactos relacionados à chuva extrema, como inundação, alagamento e deslizamento, que muitas vezes são resultados da ocupação desordenada. De encontro a isso, a região possui carência de levantamentos fundamentais, como, por exemplo, uma carta pedológica a nível municipal (CONCEIÇÃO, 2013).

Um aspecto importante para ajudar no aumento da resiliência dos morados do Jardim Zaíra é a aceitação de que vivem em uma área de risco e, por isso, são expostos aos impactos dos eventos extremos de chuva. Muitas vezes, um diagnóstico técnico, que aponte para uma remoção definitiva, é dificultado pela ausência de alternativas, levando em conta o contexto de carência da população.

É muito importante que a população entenda o ambiente em que vive, pois as pessoas atuam como o cérebro da cidade, direcionando suas atividades, em resposta às necessidades, e aprendendo com a experiência. Uma população mais preparada tem maior capacidade de sobreviver e funcionar sob condições únicas e extremas, caso contrário, ela será mais vulnerável aos desastres (GODSCHALK, 2003). Estudos compravam que uma comunidade unida é mais resiliente e tem maior capacidade de superar desastres naturais do que uma comunidade com mentalidade individualista (ESCAP, 2013).

Uma cidade que tem domínio sobre a origem dos desastres tem maior capacidade de preparação, adaptação, antecipação, aprendizagem e auto-organização, podendo ser considerada uma cidade resiliente, sendo menos vulnerável aos impactos e assumindo uma melhor preparação para lidar com a mudança, com a complexidade dos riscos existentes, com crises e perturbações múltiplas (CARVALHO et al., 2013).

Medidas como o compartilhamento de informação entre os municípios também auxiliam no aumento da resiliência. Em outros países, como no Reino Unido, cidades se beneficiam do compartilhamento de conhecimentos sobre ações quantificáveis que buscam a resiliência e a sustentabilidade (LASALLE, 2013).

\section{CONSIDERAÇÕES FINAIS}

Este trabalho analisou a resiliência em uma amostra de população do bairro Jardim Zaíra, no município de Mauá, no ABC Paulista, para analisar a resposta da população ao impacto de um evento extremo climático. Iniciou-se o estudo com a identificação das ruas mais vulneráveis a ex- tremos de chuvas no bairro e com a análise dos dados de chuva sobre a região. $\mathrm{O}$ resultado da análise das chuvas, para três postos pluviométricos e para dois períodos distintos, mostrou que, embora o acumulado da chuva mensal tenha diminuído, principalmente no verão, nos últimos 
16 anos, a concentração da chuva diária tem aumentado e se apresentado mais frequente, o que favorece eventos de chuva extrema, com impactos como inundações e deslizamentos. A estação mais próxima da área de estudo, Zaíra (E3-157), apresentou maior precipitação diária, sugerindo que, especificamente na área avaliada por meio dos questionários, os eventos de chuva extrema estão sendo mais frequentes.

Os resultados dos indicadores sociais, demográficos e sanitários no município de Mauá identificaram o Jardim Zaíra como um dos mais suscetíveis socioeconomicamente, devido ao grande adensamento populacional, à baixa renda familiar, às deficiências de serviços de saneamento básico, à baixa expectativa de vida e à sua população carente de estudos, deixando-a mais vulnerável aos impactos dos eventos extremos climáticos.

O estudo da resiliência na amostra, por meio das repostas obtidas nos questionários, mostrou que a população do Zaíra possui resiliência média, tendo os padrões filosófico ou religioso (PF) e disposicional (PD) em destaque, contribuindo para um maior grau de resiliência.

O PF evidenciou uma forte fé na amostra, podendo contribuir para suprir carências familiares e coletivas bem como para fornecer maior energia para lidar com adversidades, tornando-os mais resilientes. Já o PD avaliou a adaptabilidade, o autocontrole, a autoestima e a capacidade de aprender e expressar emoções, que não obteve maior valor pelo fato de a população não ter interesse em aprender sobre assuntos relacionados a chuvas extremas nem se informar sobre como proceder em caso de desastres relacionados à chuva.

Com isso, é possível perceber que, além de um debate em torno dos eventos extremos relacionados às mudanças climáticas e de medidas urgentes para diminuir seus impactos, é importante uma análise social e comportamental por ter influência direta na resiliência. Ao entender meIhor o comportamento da população, será mais fácil agir de forma a ampará-los e fornecer condições para que se reajustem após o impacto.
Para diminuir a vulnerabilidade dessa população a extremos climáticos, é preciso encontrar maneiras de aumentar a resiliência dela, principalmente nos padrões de comportamento relacionais e situacionais, explorando suas relações sociais e políticas.

Uma das formas é contribuir e estimular o maior conhecimento e interesse sobre a ocorrência de eventos extremos na região, além de estimular a troca de conhecimento e o sentimento de pertencimento na comunidade, pois a falta de interesse sobre o tema e sobre como reagir aos impactos bem como a falta de confiança entre os moradores foram fatores que contribuíram para uma menor resiliência na amostra estudada.

O trabalho de órgãos, como a Defesa Civil, é de grande valia para ajudar a população residente em uma área vulnerável a reconhecer que habitam uma área de risco e entender a importância das relações sociais para aumentar a capacidade de resposta a um impacto (MELO \& DOS SANTOS, 2011). Como já vem realizando nos últimos anos em Mauá.

Políticas que ajudam a entender melhor as populações podem auxiliar também no aumento de sua resiliência, assim como incentivar a conservação, a manutenção e a regeneração dos ambientes muito degradados.

Neste trabalho, fica evidente a necessidade de olhar para as relações sociais da população a fim de entender melhor os grupos menos resilientes, sendo as contribuições psicológicas e comportamentais importantes para aumentar a resiliência e, assim, diminuir a vulnerabilidade de determinado grupo.

Espera-se que este estudo sirva de base para futuras pesquisas sobre a resiliência de populações afetadas por eventos extremos, buscando maneiras de aumentar sua resiliência. Futuros trabalhos devem aprofundar esses resultados preliminares com uma análise de uma amostra maior e mais diversificada para a avaliação da resiliência, o que deve dar uma base estatística mais significativa aos resultados.

\section{AGRADECIMENTOS}

Agradeço à Defesa Civil de Mauá, especialmente à Lucas Santos Pinheiro, Jovenildo Lopes Soares, Wanderson Francisco de Lima, Sérgio Moraes de
Jesus e Sérgio Soares Nascimento por todo o apoio e suporte no fornecimento de dados e nas visitas ao Jardim Zaíra. 


\section{REFERÊNCIAS}

ANGST, R. Psicologia e resiliência: uma revisão de literatura. Psicologia Argumento, Curitiba, v. 27, n. 58, jun./set. 2009.

BELANCIERI, M. D. F.; BELUCI, M. L.; SILVA, D. V. R. D.; GASPARELO, E. A. A resiliência em trabalhadores da área da enfermagem. Estudos de Psicologia, Campinas, v. 27, n. 2, p. 227-233, 2010.

CARDONA, O. D. The need for rethinking the concepts of vulnerability and risk from a holistic perspective: a necessary review and criticism for effective risk management. In: BANKOFF, G.; FRERKS, G.; HILHORST, D. Mapping vulnerability: disasters, development and people. Londres: Earthscan Publishers, 2004. Disponível em: <http://desenredando.org/ public/articulos/2003/nrcvrfhp/nrcvrfhp_ago-04-2003.pdf>. Acesso em: 10 jul. 2014.

CARVALHO,L.;CARRASCO,Ú.;FARINHA, M.;BATISTA,S.;FERNANDES,J.M.;SOUSA,G.;LEITÃO, N. Risco, desastree resiliência: um desafio para a cidade da Amadora. In: CONGRESSO DA GEOGRAFIA PORTUGUESA, 9. Anais... Portugal: Universidade de Évora, 2013. Disponível em: <http://www.preventionweb.net/files/36750_36750riskdisasterandresilienceamado. pdf>. Acesso em: 07 mar. 2015.

CARVALHO, L. M. V.; JONES, C. Zona de Convergência do Atlântico Sul. In: CAVALCANTI, I. F. A.; FERREIRA, N. J.; SILVA, M. G. A. J.; SILVA DIAS, M. A. F. (Orgs.). Tempo e clima no Brasil. São Paulo: Oficina de Textos, 2009. p. 95-109.

CAVALCANTI, I. F. A.; KOUSKY, V. E. Frentes frias sobre o Brasil. In: CAVALCANTI, I. F. A.; FERREIRA, N. J.; SILVA, M. G. A. J.; SILVA DIAS, M. A. F. (Orgs.). Tempo e clima no Brasil. São Paulo: Oficina de Textos, 2009. Cap. 9, p. 135-147.

CECCONELLO, A. M. Resiliência e vulnerabilidade em famílias em situação de risco. Tese (Doutorado em Psicologia do Desenvolvimento)-Universidade Federal do Rio Grande do Sul, Porto Alegre, 2003. Disponível em: <http://www.lume. ufrgs.br/handle/10183/2641>. Acesso em: 14 fev. 2015.

CONCEIÇÃO, R. P. Análise das tragédias de janeiro de 2011, no bairro jardim Zaíra, município de Mauá/SP: uma análise episódica. 266 f. Dissertação (Mestrado em Geografia)-Universidade Estadual Paulista "Júlio de Mesquita Filho", Rio Claro, 2013. Disponível em: <http://base.repositorio.unesp.br/handle/11449/95542>. Acesso em: 21 fev. 2015.

CONNOR, K. M.; DAVIDSON, J. R. T. Development of a new resilience scale: The Connor-Davidson resilience scale (CDRISC). Depression and Anxiety, v. 18, n. 2, p. 76-82, 2003.

ECONOMIC AND SOCIAL COMMISSION FOR ASIA AND THE PACIFIC - ESCAP. Building Resilience to Natural Disaster and Major Economic Crises. Bangkok, 2013. Disponível em: <http://www.unescap.org/sites/default/files/ThemeStudy2013full2.pdf>. Acesso em: 11 mar. 2015.

FIN, A.; KOSECOFF, J. How to conduct surveys: a step-by-step guide. Beverly Hills: Sage, 1985.

GODSCHALK, D. R. Urban hazard mitigation: creating resilient cities. Natural Hazards Review, v. 4, n. 3, p. 136-143, 2003.

GÜNTHER, H. Como elaborar um questionário. In: PASQUALI, L. (Org.). Instrumentos psicológicos: manual prático de elaboração. Brasília: LabPAM; IBAPP, 1999.

INSTITUTO BRASILEIRO DE GEOGRAFIA E ESTATÍSTICA - IBGE. Estimativa populacional 2014. IBGE Cidades, 2014. Disponível em: <http://www.cidades.ibge.gov.br/xtras/home.php>. Acesso em: 30 jul. 2015.

INTERGOVERNMENTAL PANEL ON CLIMATE CHANGE - IPCC. Climate change 2001: impacts, adaptation and vulnerability- contribution of working group 2 to the IPCC Third Assessment Report. Cambridge: Cambridge University Press, 2001.

. Climate change 2014: impacts, adaptation, and vulnerability. IPCC, 2014. v. 1. 
JOB, F. Resiliência na organização: estudo de caso da medição e avaliação da resiliência de indivíduos em uma organização industrial. Revista da Faculdade de Ciências Médicas de Sorocaba, Sorocaba, v. 5, n. 1, 2003. Disponível em: <http://revistas.pucsp.br/index.php/RFCMS/article/view/120>. Acesso em: 29 jul. 2014.

LASALLE, J. L. Global Sustainability Perspective. March 2013. Disponível em: <https://www.joneslanglasalle.com/GSP/ en-gb/Documents/Global-Sustainability-Perspective-March-2013.pdf>. Acesso em: 31 jul. 2014.

MARENGO, J.; SCHAEFFER, R.; PINTO, H. S.; ZEE, D. M. W. Mudanças climáticas e eventos extremos no Brasil. Fundação Brasileira para o Desenvolvimento Sustentável, 2010. Disponível em: <http://www.fbds.org.br/cop15/FBDS_ MudancasClimaticas.pdf>. Acesso em: 20 jul. 2014.

MARTINS, R. A.; FERREIRA, L. C. Uma revisão crítica sobre cidades e mudança climática: vinho velho em garrafa nova ou um novo paradigma de ação para a governança local? Revista de Administração Pública, Rio de Janeiro, v. 45, n. 3, 611-641, 2011.

MELO, C. A.; DOS SANTOS F. A. As contribuições da psicologia nas emergências e desastres. Psicólogo inFormação, São Paulo, ano 15, n. 15, 2011. Disponível em: <https://www.metodista.br/revistas/revistas-ims/index.php/PINFOR/ article/viewFile/3177/3045>. Acesso em: 11 mar. 2015.

NASA. NOAA Find 2014 Warmest Year in Modern Record. Release 15-010. Jan. 2015. Disponível em: <http://www.nasa.gov/ press/2015/january/nasa-determines-2014-warmest-year-in-modern-record/\#.VOOPyUJZ9-w>. Acesso em: 18 jul. 2014.

OLIVEIRA, M. A. D.; NAKANO, T. D. C. Revisão de pesquisas sobre criatividade e resiliência. Temas em Psicologia, v. 19, n. 2, p. 467-479, 2011.

PETERNELLI, L. A. Capítulo 9: regressão linear e correlação. 2014. Disponível em: <http://www.dpi.ufv.br/ p peternelli/ inf162.www.16032004/materiais/CAPITULO9.pdf>. Acesso em: 18 out. 2014.

POLK, L. V. Toward a middle-range theory of resilience. Advances in Nursing Science, Washington, v. 19, n. 3, p. 1-13, 1997.

SABBAG, P. Y. Resiliência: competência para enfrentar situações extraordinárias na vida profissional. Campus Elsevier, 2012. v. 1. 240p.

SCHUMAN, H.; KALTON, G. Survey methods. In: LINDZEY, G.; ARONSON, E (Eds.). Handbook of social psychology. 3a. ed. Nova York: Random House, 1985. v. 1. p. 635-697.

SEWARD, L. E.; DOANE, D. P. Estatística aplicada à administração e economia. São Paulo: Bookman, 2014. v. 4. p. 143-145.

SILVA, A. L. C. Introdução à análise de dados. Rio de Janeiro: E-papers, 2009. v. 1. p. 62-63.

UN-HABITAT. United Nations Human Settlements Programme. Cities and climate change: policy directions. Londres: Earthscan, 2011. Disponível em: <http://www.citiesalliance.org/sites/citiesalliance.org/files/CA_Images/UNH_ GRHS2011_CitiesClimateChange.pdf>. Acesso em:14 fev. 2015.

VALENCIO, N.; SIENA, M.; MARCHEZINI, V.; GONÇALVES, J. C. Sociologia dos desastres. Construção, interface e perspectivas no Brasil, São Carlos, 2009. Disponível em: < http://www.crpsp.org.br/portal/comunicacao/diversos/ mini_cd_oficinas/pdfs/Livro-Sociologia-Dos-Desastres.pdf >. Acesso em: 11 mar. 2015.

VALVERDE, M. C. A interdependência da vulnerabilidade climática à socioeconômica na região do ABC Paulista. Ambiente e Sociedade. Submetido em Dezembro de 2015. Aceito para publicação, Abril de 2017.

VIANA, Diego. Uma megalópole sem água. Página 22, n. 93, p. 32-39, 2015. Disponível em: <http://bibliotecadigital.fgv. br/ojs/index.php/pagina22/article/download/46891/44512>. Acesso em: 15 fev. 2015. 